\title{
Arcjet Ablation of Stony and Iron Meteorites
}

\author{
Parul Agrawal ${ }^{1}$ \\ AMA, Inc. at NASA Ames Research Center, Moffett Field, CA, 94035. \\ Peter Jenniskens ${ }^{2}$ \\ SETI Institute, Mountain View, CA 94043. \\ Eric C. Stern ${ }^{3}$, James O. Arnold ${ }^{4}$ and Yih-Kanq Chen ${ }^{5}$ \\ NASA Ames Research Center, Moffett Field, CA, 94035.
}

\begin{abstract}
A test campaign was conducted placing meteorites in the $60 \mathrm{MW}$ plasma Arcjet Interaction Heating Facility at NASA Ames Research Center, with the aim to achieve flight-relevant conditions for asteroid impacts in Earth's atmosphere and to provide insight into how meteoritic materials respond to extreme entry heating environments. The test conditions at heat flux of $4000 \mathrm{~W} / \mathrm{m}^{2}$ and $140 \mathrm{kPa}$ stagnation pressure are comparable to those experienced by a 30-meter diameter asteroid moving at $20 \mathrm{~km} / \mathrm{s}$ velocity at $65 \mathrm{~km}$ altitude in the Earth's atmosphere. Test objects were a stony type $\mathrm{H5}$ ordinary chondrite (Tamdakht) and an iron type IAB-MG meteorite (Campo Del Cielo), and included the terrestrial analogs Dense Flood Basalt and Fused Silica. All samples were exposed for only a few seconds in the plasma stream. Significant melt flow and vaporization was observed for both the stony and iron meteorites during exposure. Mass loss from spallation of fragments was also observed. Vapor emitted atomic lines from alkali metals and iron, but did not emit the expected MgO molecular band emissions. The meteoritic melts flowed more rapidly, indicating lower viscosity, than those of Fused Silica. The surface recession was mapped. The effective heat of ablation derived from this showed that ablation under these conditions occurred in the melt-dominated regime. Ablation parameters have an effect on ground damage estimates. A bias in ablation parameters towards the melt-dominated regime would imply that impacting asteroids survive to lower altitude, and therefore could possibly have airbursts with a larger ground damage footprint.
\end{abstract}

\section{Nomenclature}

\begin{tabular}{|c|c|c|c|c|c|}
\hline ATAP & $=$ & Asteroid Threat Assessment Project & $\sigma$ & $=$ & Stefan-Boltzmann coefficient \\
\hline CFD & $=$ & Computational Fluid Dynamics & $\varepsilon$ & $=$ & Emissivity \\
\hline $\mathrm{CT}$ & $=$ & Computed Tomography & $\mathrm{T}_{\text {sensor }}$ & $=$ & $\begin{array}{l}\text { Recorded temperature from } \\
\text { pyrometer or infrared camera }\end{array}$ \\
\hline DPLR & $=$ & Data Parallel Line Relaxation code & $\mathrm{T}_{\text {target }}$ & $=$ & Sample temperature \\
\hline IHF & $=$ & Interaction Heating Facility & $\mathrm{T}_{\text {backgroud }}$ & $=$ & Background (ambient) temperature \\
\hline IR & $=$ & Infrared & & & \\
\hline LEAF & $=$ & Lunar Environment Arcjet Facility & & & \\
\hline SMD & $=$ & Science Mission Directorate & & & \\
\hline TUFI & $=$ & $\begin{array}{l}\text { Toughened Unipiece Fibrous } \\
\text { Insulation }\end{array}$ & & & \\
\hline
\end{tabular}

\footnotetext{
${ }^{1}$ Senior Research Scientist, Thermal Protection Materials Branch. Presently, Projects Management Division, Mail Stop $244-2$. Senior Member AIAA.

${ }^{2}$ Senior Research Scientist, SETI Institute, Mountain View, CA 94043. Member AIAA.

${ }^{3}$ Research Scientist, Thermal Protection Materials Branch, Mail Stop 234-1. Member AIAA.

${ }^{4}$ Aerospace Engineer, Thermal Protection Materials Branch, Mail Stop 234-1. Member AIAA.

${ }^{5}$ Senior Scientist, Entry Systems and Technology Division, Mail Stop 229-3. Fellow AIAA.
} 


\section{Introduction}

$\mathrm{T}$ he Asteroid Threat Assessment Project (ATAP) under NASA's Science Mission Directorate (SMD) is created to provide information to decision makers in the event of a pending strike by an asteroid that could cause significant loss of life and devastation to the Earth's surface (land or water via a tsunami) ${ }^{1}$. The atmospheric entry speeds of these asteroids are typically 12 to $30 \mathrm{~km} / \mathrm{s}$ and their sizes vary from single meters to kilometers, corresponding to hundreds or thousands of kilotonnes of TNT (kt) of kinetic energy even for small 20 to $50-\mathrm{m}$ sized asteroids, respectively ${ }^{2}$. Known impacts include the $500 \mathrm{kt} 2013$ Chelyabinsk airburst event ${ }^{3}$ and the $\sim 15,000$ kt 1908 airburst over Tunguska ${ }^{4}$. Both caused significant surface damage and injured people on the ground ${ }^{3}$, despite fragmenting during flight and depositing their kinetic energy almost entirely into the atmosphere.

ATAPs approach to reliably simulate asteroid entry and breakup is to adapt to the problem the hardware techniques and software tools NASA has developed for the design of atmospheric-entry spacecraft. The $60 \mathrm{MW}$ plasma Arcjet Interaction Heating Facility (IHF) at NASA Ames Research Center is such technique, normally used to expose spacecraft thermal protection systems to entry-like environments. Similarly, the IHF can be used to provide insights into meteoric materials response to very hostile entry heating environments.

In October 2016 and July 2017, the ATAP project executed a pathfinder Arcjet test campaign to investigate the ablative behavior of a representative stony and iron meteorite, in addition to terrestrial analogs like fused silica and basalt, as well as emulate their emission signatures observed in remote sensing. The test had two primary objectives, namely to provide quantitative data for meteoroid ablation model development, and to do an in-situ investigation of the emission from the ablation products by optical spectroscopy. In addition to these primary objectives, secondary objectives were to investigate the effect of heating on pre-existing cracks and microstructure in the test samples through pre- and post-test X-ray Computed Tomography (CT) scan characterization, and to provide pathfinder data for informing a planned combined radiative and convective heating campaign.

Meteoroid entries occur at much higher speeds than typical spacecraft reentries. Melting, evaporation, spallation, and fragmentation play a more important role. State-of-the-art meteoroid ablation models are based primarily on observational data from meteoroid light curves and meteor spectroscopy in remote sensing. There is little to no experimental data on meteoritic material at flight relevant conditions. The experiment provided the opportunity to apply these techniques to study the excited ablated species and reconcile models that predict the abundances of atoms and molecules in the ablated vapor. It is known from meteor spectra that the atomic lines from metallic species dominate the spectrum, but models predict an important contribution from molecular band emissions. Data from this effort inform and validate radiation models for meteoritic ablation products.

This paper provides the details of the test environments, the article design, results from the Arcjet test campaign that include still images of high speed videos, surface temperature data collected by pyrometers and infrared cameras, recession profiles and magnitude, CT scan images as well as data from optical spectroscopy. Results are compared to pre-test model predictions.

\section{Experimental Techniques}

The stony meteorite test article was a sample of the H5 type Tamdakht meteorite ${ }^{5}$, which fell near Ouarzazate, Morocco on December 20, 2008. This was a significant fall from a several-meter sized asteroid entry that produced a strewn field of approximately $25 \mathrm{~km} \times 2 \mathrm{~km}$ and two small impact craters, one $\sim 1.1 \mathrm{~m}$ diameter and $70 \mathrm{~cm}$ depth, and the other $\sim 20 \mathrm{~cm}$ diameter and $10 \mathrm{~cm}$ depth. ${ }^{5}$ Several large fragments were recovered from this fall. The larger pieces show fusion crust, a glass layer remnant of the ablation layer created during Earth atmospheric entry. The meteorite has abundant chondrules, solidified droplets of silicates, with sizes ranging from 0.1 to $1.5 \mathrm{~mm}$. The dominant minerals are iron magnesium silicates (olivine, orthopyroxene, feldspar), iron sulfides (troilite) and metalic iron (kamacite and taenite). It also has about $15 \%$ of a fine matrix phase of silicates, metals and metal sulfides, and $10 \%$ voids in the form of porosity.

The iron meteorite test article was a sample of IAB-MG type Campo Del Cielo, a tens of meter sized asteroid, the fall of which occurred $\sim 4,000$ years ago in Argentina. Several craters were formed by multi-ton fragments of a type IAB-MG iron meteoroid with abundant silicate inclusions. ${ }^{6}$ The average composition of the Campo del Cielo meteorites (excluding inclusions) is $92.6 \% \mathrm{Fe}, 6.67 \% \mathrm{Ni}, 0.43 \% \mathrm{Co}, 0.25 \% \mathrm{P}, 87 \mathrm{ppm} \mathrm{Ga}, 407 \mathrm{ppm} \mathrm{Ge}$, and $3.6 \mathrm{ppm}$ Ir. ${ }^{7}$ The meteorites contain several hard inclusions. These inclusions are composed of a variety of rock types, which consist of silicates and variable amounts of graphite and minor metal and sulfides. ${ }^{7}$ The material has no voids.

All test articles were machined into 45-degree sphere cones in the shape of a mini probe as shown in Figure 1. This shape was selected to control the flow field around the sample and provide high heating rates at the nose as well as significant shear stress. The dimensions were $3.07 \mathrm{~cm}$ base diameter and $1.525 \mathrm{~cm}$ height, with $0.635 \mathrm{~cm}$ nose radius. The test articles were attached to a LI-2200 insulator back plate (the same material used for insulation in shuttle 
tiles) to insulate the sample from the sample holder. A TUFI (Toughened Unipiece Fibrous Insulation) coating was applied to the LI-2200 back-plate to ensure that it can sustain temperatures up to $1300^{\circ} \mathrm{C}$. The insulator was attached to a graphite holder (Fig. 1). Resbond-940LE epoxy was applied on the top and bottom side of the LI-2200 insulator to bond it to the sample and holder. A Tungsten rod, in addition to epoxy was used to attach the graphite holder to the sample via an insulator plate. Subsequently, the sample holder was attached to a water-cooled copper cone with the help of a model adapter. Cones and sample were mounted on arms that moved the sample into the plasma flow.

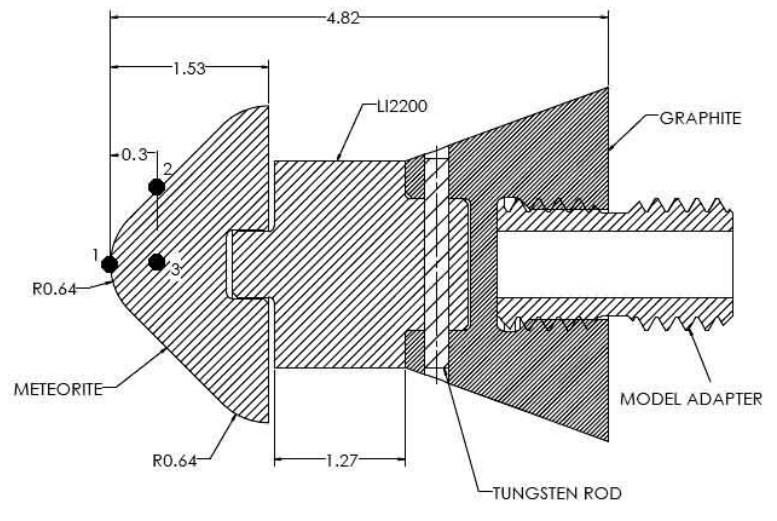

SECTION A-A

Figure 1. Arcjet test model dimensions and assembly. Black dots mark positions to which pyrometers are pointed.

The surface recession was measured by both scanning the surface of the models with a laser and by using X-ray 3D Computed Tomography, both before and after the experiment.

The test campaign was completed in two phases. In the first phase in October 2016, the stony Tamdakht meteorite was tested together with a basalt and a fused silica sample for reference. Due to water leaks towards the end of second day, the facility was shut down for repairs and the remaining samples were tested during the second phase in July of 2017. In July, the iron Campo Del Cielo meteorite was tested together with an additional sample of Tamdakht and a fused silica sample.

The IHF at NASA Ames Research Center was utilized at maximum possible heat flux in a well-controlled flow environment by operating the arc heater at near maximum current and flow rates using the well characterized $15.25 \mathrm{~cm}$ (6 inch) diameter nozzle.

Table 1: Experimental conditions.

\begin{tabular}{|c|c|c|c|c|c|c|c|c|c|}
\hline $\begin{array}{l}\text { Experiment } \\
\text { Date }\end{array}$ & $\begin{array}{l}\text { Nozzle } \\
\text { Diameter } \\
(\mathrm{cm})\end{array}$ & $\begin{array}{l}\text { Average } \\
\text { Heat } \\
\text { Flux } \\
\left(\mathrm{W} / \mathrm{cm}^{2}\right)\end{array}$ & $\begin{array}{l}\text { Average } \\
\text { Stagnation } \\
\text { Pressure } \\
(\mathrm{kPa})\end{array}$ & $\begin{array}{l}\text { Bulk Sonic } \\
\text { Flow } \\
\text { Enthalpy } \\
(\mathrm{MJ} / \mathrm{kg})\end{array}$ & $\begin{array}{l}\text { Main } \\
\text { Air } \\
(\mathrm{gm} / \mathrm{s})\end{array}$ & $\begin{array}{l}\text { Add. } \\
\text { Air } \\
(\mathrm{gm} / \mathrm{s})\end{array}$ & $\begin{array}{l}\text { Ar. } \\
(\mathrm{gm} / \mathrm{s})\end{array}$ & $\begin{array}{l}\text { Arc } \\
\text { Current } \\
\text { (Amp) }\end{array}$ & $\begin{array}{l}\text { Distance } \\
\text { from } \\
\text { Nozzle } \\
(\mathrm{cm})\end{array}$ \\
\hline $10 / 17 / 2016$ & 15.25 & 3409.35 & 126.105 & 20.6 & 740 & 55 & 55 & 5944 & 10.16 \\
\hline $7 / 26 / 2017$ & 15.25 & 3290.8 & 126.5 & 20.7 & 740 & 55 & 54 & 6018 & 10.16 \\
\hline
\end{tabular}

The flow conditions were measured using a 13 $\mathrm{mm}$ coaxial heat flux gage and a $9 \mathrm{~mm}$ pressure gage. The instrumental settings and the measured values from these gages are listed in Table 1.

The test sample was placed $10.16 \mathrm{~cm}$ (no-flow distance) behind the nozzle exit in a low-pressure chamber, which had optical viewing ports on three sides (East, West and Top). On the East port (Fig. 2), several instruments were set up for video recording, surface temperature measurements, and optical spectroscopy. A RED Epic digital cinema camera (Fig. 2A), a high spatial resolution $(5120 \mathrm{x}$ 2700 pixels) color camera, was used to document details of the spallation, melt flow and gas flow in great spatial detail and in high dynamic resolution. RED Epic video was taken with a sequence of three different exposure times, designed to increase the dynamic range. The shortest exposure time proved to provide the best intensity scale.

A Phantom V12.1 high frame rate (1500 frames/s) and high definition (HD) imager (Fig. 2B) was used to capture spallation and ablation features. The camera's field of view captured video of the entire sample during the exposure.

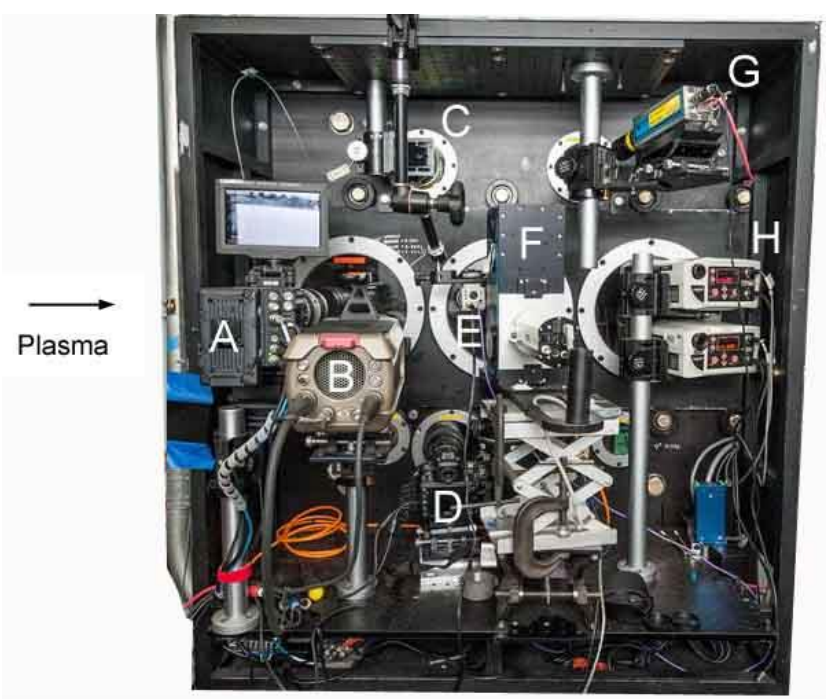

Figure 2. Instrumental layout for imaging and spectroscopy. (A) RED Epic; (B) Phantom; (C) unoccupied; (D) Digital Still Camera; (E) Hitachi KP-D20A camera; (F) Echelle Spectrometer; (G) HD Video Camera; (H) Pyrometers. 
The spectroscopic signatures of the plasma and ablation products were probed with a high spectral resolution miniature Echelle spectrograph (Fig 2F). The Echelle spectograph is a modified Catalina Scientific SE 200 Echellette, equipped with a Nikon $105 \mathrm{~mm}$ f4.5 UVNikkor lens and square ( 97 x 73 micron) slit. The Echelle instrument has been used before in airborne observations of artificial and natural meteors in slit-less mode ${ }^{8}$. For this occasion, the instrument was equipped with a slit to provide high $(\mathrm{R} \sim 1,000)$ resolution spectroscopy from 300 to $880 \mathrm{~nm}$ at a rate of 10 frames per second. The spectroscopy probes one line of sight along a $\sim 0.17 \times 0.13 \mathrm{~cm}$ area at the distance of the sample $(\sim 72 \mathrm{~cm})$ immediately behind the test object. For phase 1, the line of sight was selected immediately above the interface of the LI-2200 stem and graphite conical holder. For the phase 2 test, the line of sight was selected at the stagnation surface (nose) of the test samples. The exact position of the line of sight measured could only be determined after the test, because the flow moved the test sample a variable amount relative to the rest position. To determine the measured line of sight, we compared the position of the test object before, after, and during the measurement. The absolute irradiance levels were calibrated against a NIST-calibrated calibration lamp (The 2-inch sphere), placed at the position of the test sample.

As a backup, we used two low $\sim 1$-nm resolution fiber-fed Ocean Optics spectrographs that measured a global view of the emission in the 400-700 nm (West) and 640-1125 nm (East) wavelength range of the test object, as well as a small Ximea hyper-spectral imaging camera (not shown in Fig. 2). This data is not discussed here.

Optical pyrometers (Fig. 2G) and a mid-Infra-Red camera (Fig. 2H) were used to measure the surface temperature during the exposure. The mid-IR camera was a Mikron MCS640. The optical pyrometers, named M668L, M190HX and M190R2, were aligned to the test article as shown in Figure 1. One pyrometer, M668L, was mounted inside the test chamber, directly focusing on the stagnation point, the nose of the test samples. The two other pyrometers were mounted outside the west window, looking through the mirror, and were focused on a spot away from the stagnation point on the conical surface (Fig. 1). A small correction was required to compensate for the window emission. The temperature measured by the pyrometer can be related to the actual target temperature and the background temperature by the following equation:

$$
\sigma T_{\text {sensor }}^{4}=\varepsilon \sigma T_{\text {target }}^{4}+(1-\varepsilon) \sigma T_{\text {background }}^{4}
$$

Here $\sigma$ is the Stefan-Boltzmann coefficient, $T_{\text {sensor }}$ is the measured value from pyrometers, $T_{\text {target }}$ is sample temperature, $\varepsilon$ is the sample emissivity, and $\mathrm{T}_{\text {background }}$ is the background temperature. Equation (1) can be re-written:

$$
T_{\text {target }}=\sqrt[4]{\frac{T_{\text {sensor }}^{4}-(1-\varepsilon) \cdot T_{\text {background }}^{4}}{\varepsilon}}
$$

If the background temperature is significantly smaller than the sample temperature, Equation (2) can be further simplified as:

$$
T_{\text {target }}=\sqrt[4]{\frac{1}{\varepsilon}} T_{\text {sensor }}
$$

Equation (3) was used to account for emissivity of various materials when reporting the data from pyrometers. Table

Table 2. Assumed emissivity values for materials.

\begin{tabular}{ll}
\hline Material & Emissivity \\
\hline Dense Flood Basalt & 0.90 \\
Stony Meteorite (Tamdakht H5) & 0.85 \\
Iron Meteorite (Campo Del Cielo IIAB) & 0.30 \\
Fused Silica & 0.30 \\
\hline
\end{tabular}

2 lists the emissivity values that were assumed for each material while processing the data. These values are suitable for solids at room temperature and it is possible that melts at higher temperature may have slightly different values.

A 5-second exposure time was planned for each sample, based on pre-test thermal response analysis of fused silica. However, there was a provision to stop the test earlier than 5 seconds if required. Indeed, several exposures were stopped after 2 seconds due to higher than expected ablation and melting.

\section{Results}

\section{A. Basalt}

Dense Flood Basalt is a suitable terrestrial analog for measuring the required exposure times when imaging the ablation of meteorites. Basalt was the very first sample that was tested in this campaign. Significant spallation and melting was 
observed as soon as the sample came into the plasma stream. Figure 3 shows the frames captured by the high speed camera at various times from the moment of insertion. At 0.7 seconds of exposure, a significant fraction of material fractured from the shoulder of the sample. After 1.5 seconds of exposure, significant wide-spread melting occurred that caused the flow to reach the LI-2200 stem and graphite holder. After 2.0 seconds, the melt became significant enough that it started to deposit on the copper cooling cone. Blue light on the flank of the sample is reflected light from the Arcjet plasma. Small fragments exposed by that same blue light can be seen when they emerge from behind the sample (in focus only when they are at the same distance from the camera as the sample). After $\sim 4.5$ seconds, the sample was fully ablated and the test was stopped. The last panel shows LI-220 melting.
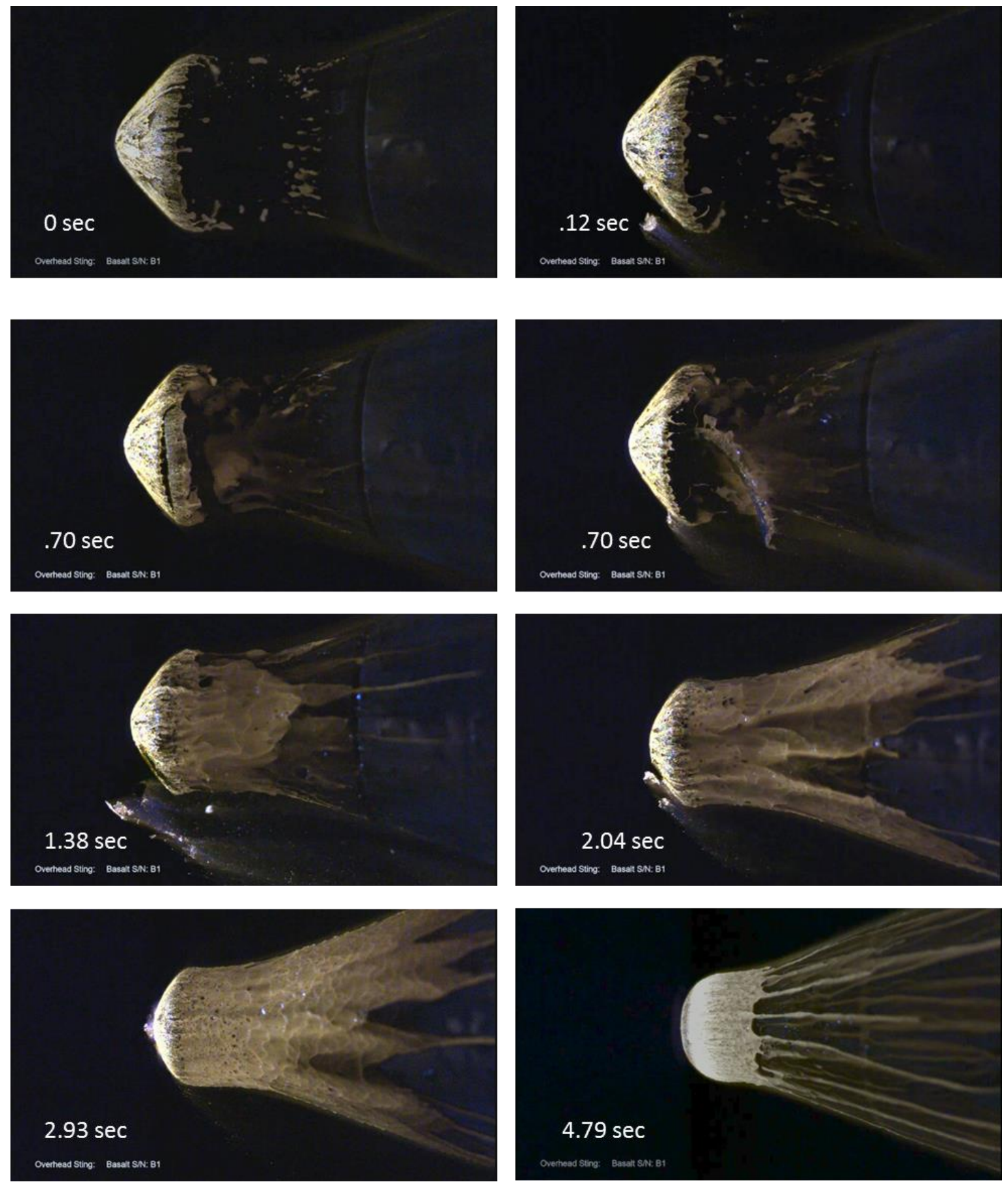

Figure 3. Basalt test model at different times from the start of exposure to the Arcjet plasma. 
This run provided important insights in terms of how fast the samples were receding due to melting and spallation, and helped determine the exposure times for spectroscopy and imaging required for the meteorite samples.

The surface temperature evolution during exposure of the Basalt sample is shown in Figure 4 (top). The stagnation surface temperature reached $2000^{\circ} \mathrm{C}$ (pyrometer M668L). This is well above the melting point of basalt, which ranges from $980^{\circ} \mathrm{C}$ to $1200^{\circ} \mathrm{C}$ for various types. ${ }^{9}$ The $\mathrm{M} 190 \mathrm{HX}$ pyrometer that focused on the flank area measured a near constant $1500^{\circ} \mathrm{C}$ (Fig. 4), which is still well above the melting point. The sudden drop of stagnation temperature after 2 seconds is due to fast receding of the stagnation point. Post-test recession analysis from laser scanning could not be performed for Basalt, as the sample was fully ablated.

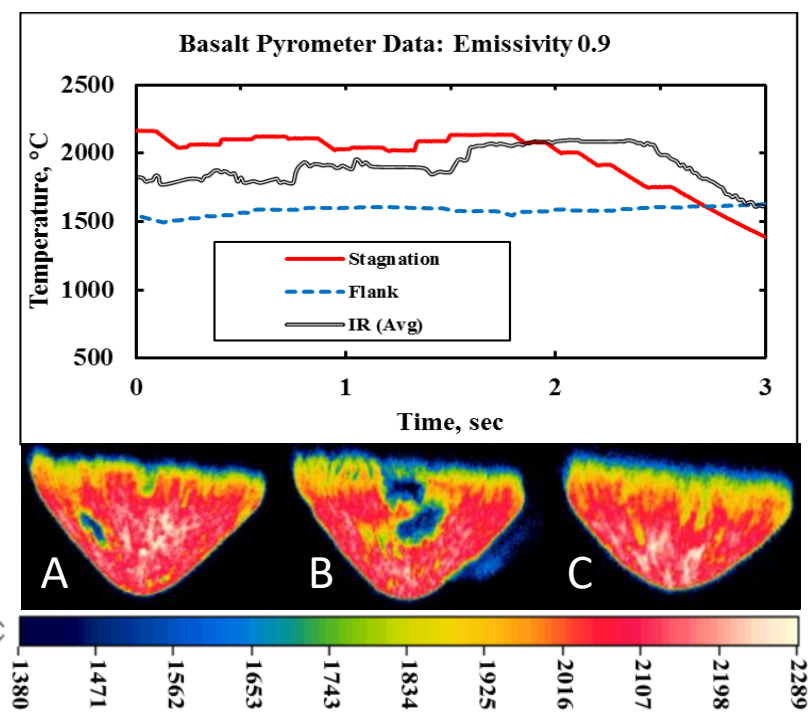

Figure 4. Temperature profile from two pyrometers and as deduced from infrared imaging. (A) $0.5 \mathrm{~s}$, (B) $1.3 \mathrm{~s}$, (C) $2.5 \mathrm{~s}$.
Figure 4 (bottom) shows the temperature distribution over the surface of the Basalt test sample derived from mid-IR imaging. The data shows the surface temperature reaching to $2000^{\circ} \mathrm{C}$ (red), which is consistent with the pyrometer measurements. Cooler areas (blue) and extended emissions are due to spallation, the release of small fragments during the exposure. Panel B shows the aftermath of a large spalling event.

Basalt spectra were recorded over a period of 5 seconds. One of the captured Basalt spectra recorded by the Echelle instrument is shown in Figure 5. To the left is the raw data, with wavelength over each Echelle order running left to right and top to bottom. To the left is shown the extracted spectrum. The exposure level was such that emissions above $600 \mathrm{~nm}$ wavelength was fully saturated. Emissions at shorter wavelengths are well exposed, and show many emission lines. The main emissions are from copper (a contamination effect due to the Arcjet electrodes), and ablated basalt species of sodium, iron and calcium. The species concentration changed with time. A $2070 \pm 20 \mathrm{~K}$ blackbody curve can be fitted to the 450-600 nm part of the spectrum, close to the melt temperature measured by the M668L pyrometer at that time. There is also excess continuum emission at near-UV and blue wavelengths $300-400 \mathrm{~nm}$, which may originate from reflected Arcjet emissions.
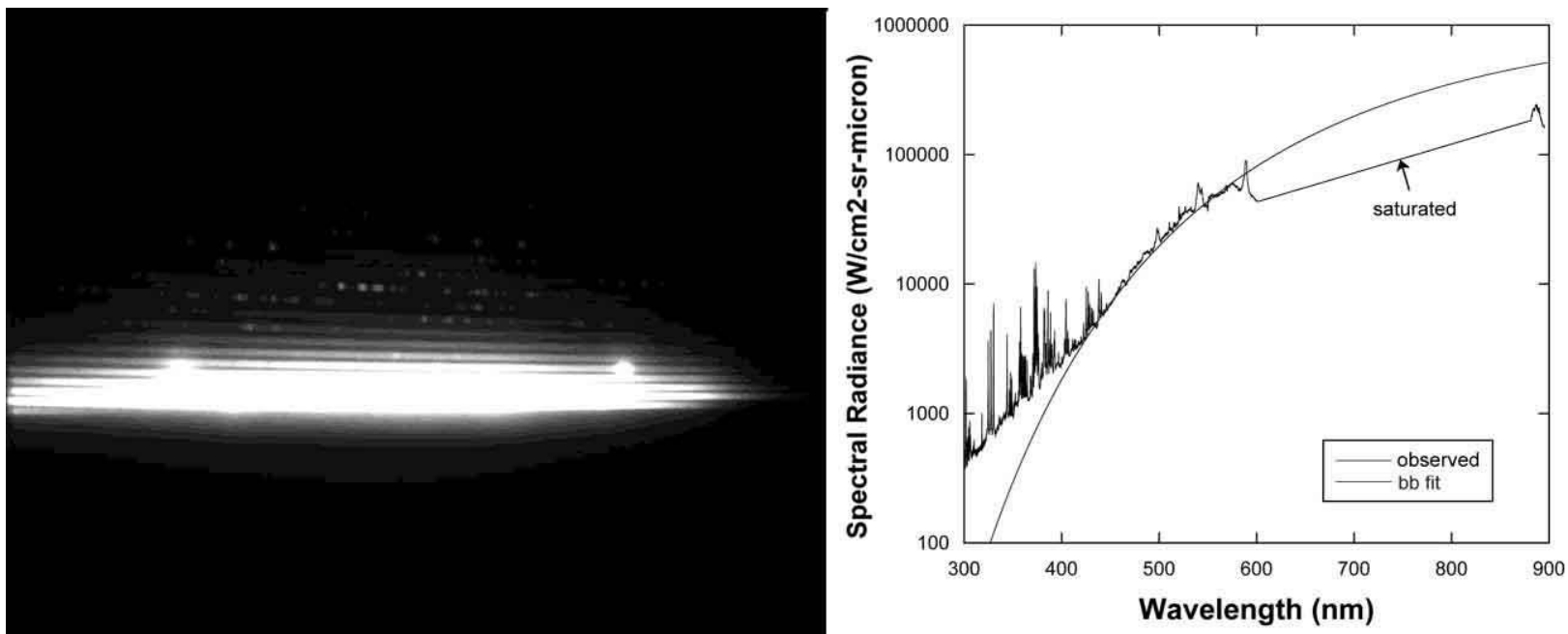

Figure 5. Echelle spectrum: raw data (left) and extracted spectrum (right). 


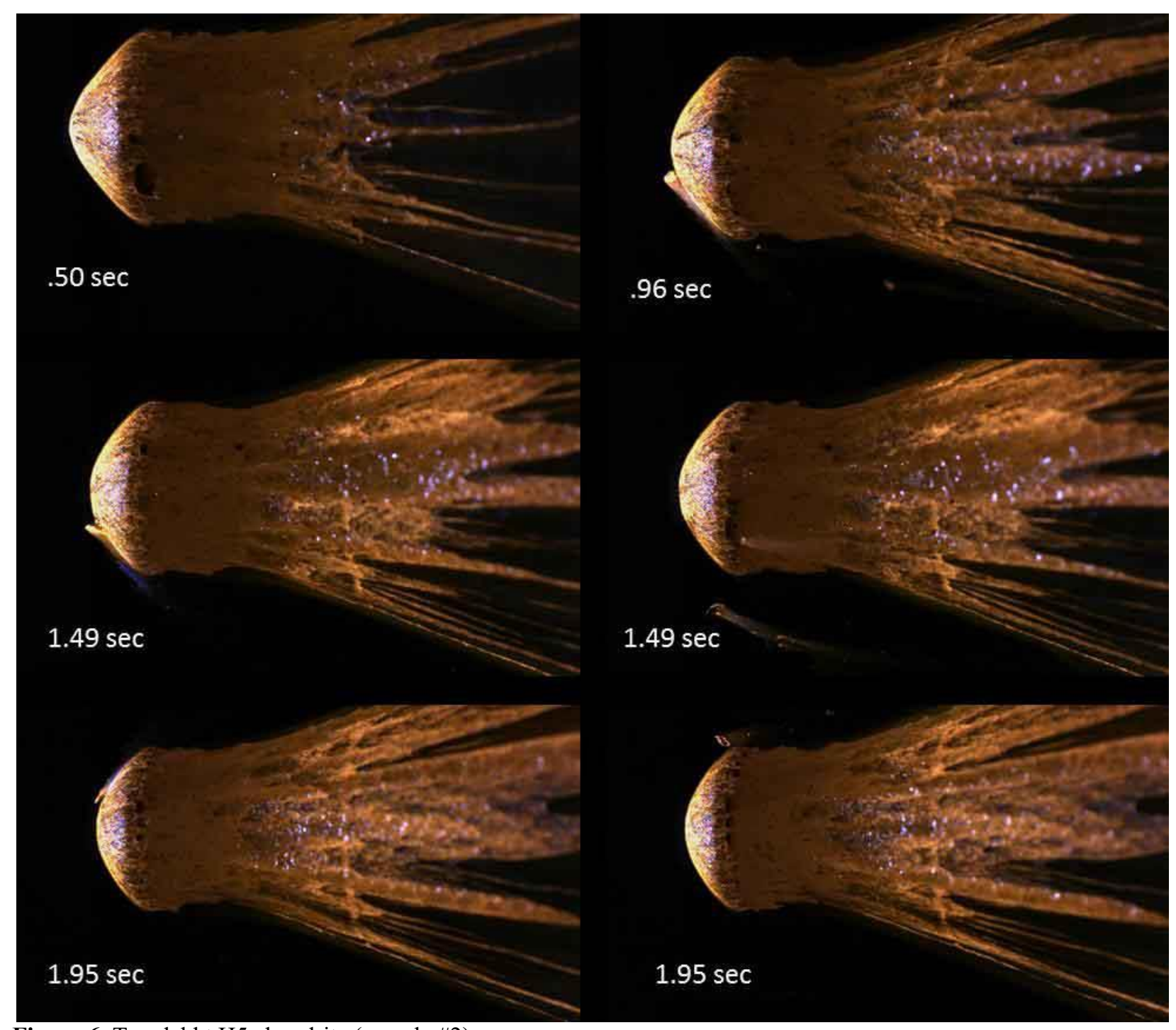

Figure 6. Tamdakht H5 chondrite (sample \#2).

\section{B. Stony meteorite (Tamdakht)}

Two Tamdakht samples were tested, one on each test run. After observing the response of the Basalt sample, it was decided to expose Tamdakht samples for only 2 seconds in the plasma stream, in order to be able to measure the recessed surface by laser scanning and X-ray CT for ablation modeling.

Figure 6 shows selected high frame-rate images of Tamdakht sample \#2 in the plasma stream. The melting started as soon as the sample was exposed in the plasma stream and appeared to flow more readily than the Flood Basalt sample. After 0.5 seconds of exposure, the melt flow was so significant that it started to reach the LI-2200 stem, graphite holder, and the copper cooling cones as shown in Fig. 6.

While there were similar events of spallation, they appeared less prominent as was the case with Basalt. In some fragmentation events, emission of blue light was observed, from fragments reflecting the Arcjet emissions. Even though there were surface and subsurface cracks on both the Tamdakht samples, we were not able to correlate spallation event sites to those of cracks. Fracturing did not occur along these pre-existing cracks. The few fragmentations we witness in Tamdakht were significantly smaller than the crack site that was observed in pre-test samples.

The surface temperature history for Tamdakht is shown in Fig. 7. The stagnation surface temperature is in the range of $2000^{\circ} \mathrm{C}$ to $2100^{\circ} \mathrm{C}$. The temperature at the conical surface away from nose was $\sim 1600^{\circ} \mathrm{C}$. These values are well above the predicted theoretical melt temperature. 


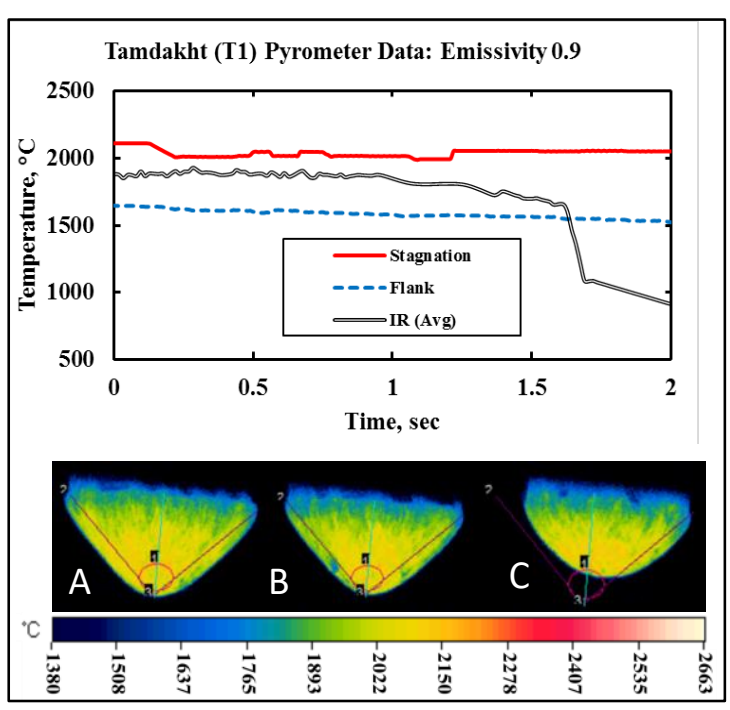

Figure 7. Temperature profiles of stony meteorite Tamdakht. (A) $0.1 \mathrm{~s}$; (B) $0.6 \mathrm{~s}$; (C) $1.9 \mathrm{~s}$

Temperature contours for the Tamdakht sample based on the mid-IR imaging are shown in Fig. 7 (bottom). Similar to Basalt, the surface temperature exceeded $2000^{\circ} \mathrm{C}$ (well above the expected melting point of Tamdakht and even above the boiling point). The evidence of fragmentation was seen in mid-IR videos also (Fig. 7B), but it was not as pronounced as it was in Basalt, despite the visible microstructure of basalt being smoother than that of Tamdakht.

The temperature values measured by the mid-IR imager fall in between the stagnation point and flank temperatures measured by the pyrometers and are consistent with the expected values. We did notice a gradual drop in the value, which may be due to the position of IR camera and viewing angle with respect to sample (not shown).

Post-test examination of the sample revealed a meteoritic melt coating on the LI-2200 stem and graphite holder.

Figure 8 summarizes the recession measurements for one of the two Tamdakht samples obtained pre- and post Arcjet exposure. The laser surface scan data shows a center recession of $6.22 \mathrm{~mm}$ for Tamdakht sample\#1 and $7.05 \mathrm{~mm}$ for Tamdakht sample \# 2 after 2 seconds of exposure. The 3D CT (computed Tomography) scan shows a recession height of $6.68 \mathrm{~mm}$ for Tamdakht sample \#1 (Fig. 8). This value differs with that obtained by the laser scan measurements by only $7 \%$.

As expected, the recession is greatest near the stagnation

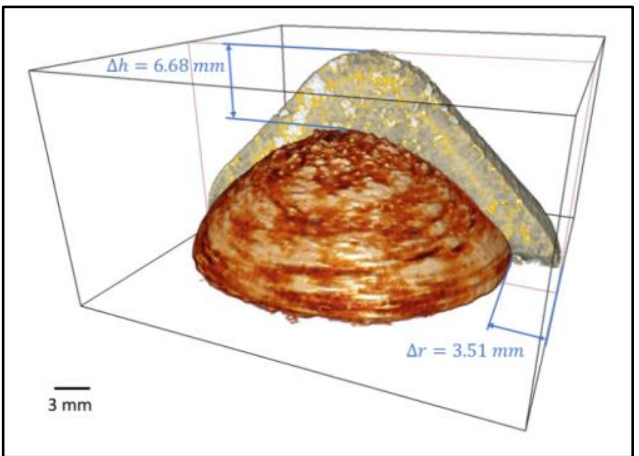

Figure 8. Recession profile for Tamdakht in 3D CT scans. point, causing a more blunt shape over time. Recession is about $3.51 \mathrm{~mm}$ at the outer edge (Fig. 8).

During the exposure of Tamdakht, the shock front emitted significant emission, as seen in the high contrast Red Epic image of Figure 9. Along the copper support cone was a layer of yellow gas, which emanated from the side of the test sample. This, presumably, was ablated meteoric vapor.

Emission spectra were recorded over a period of $\sim 2$ seconds. The exact location of the measured line of sight through the flow field (white dot in Fig. 9) was determined by comparing video imaging of the test sample when it was in the flow and when it was at rest afterwards, and aligning the spectrometer with a 1-mm wide light source at the position of the sample. In run $\# 2$, a laser was used to illuminate the stagnation point of the sample in the rest position. The corresponding point that was probed during exposure is shown in Fig. 9.

One of the captured Tamdakht\#1 spectra as recorded by Echelle is shown in Fig. 10. The frames were well exposed, with no saturation in the continuum. The Tamdakht spectra were extracted, sampled at 0.01 -nm steps, and calibrated in both wavelength and intensity. Figure 10 shows an extracted spectrum with the continuum background subtracted and the identified emission lines pertaining to various atomic species.

Strong alkali metal atomic lines of $\mathrm{Li}, \mathrm{Na}, \mathrm{K}$ and $\mathrm{Rb}$ are detected. These are excited from the ground state, indicative of low excitation temperature conditions. The spectrum also contains meteoritic emissions of $\mathrm{Fe}$ and $\mathrm{Cr}$. The continuum emission traces the temperature of the melt. Emissions from $\mathrm{Cu}$ were also present in the free-flow spectrum, but originated in the Arcjet itself (marked by *). 


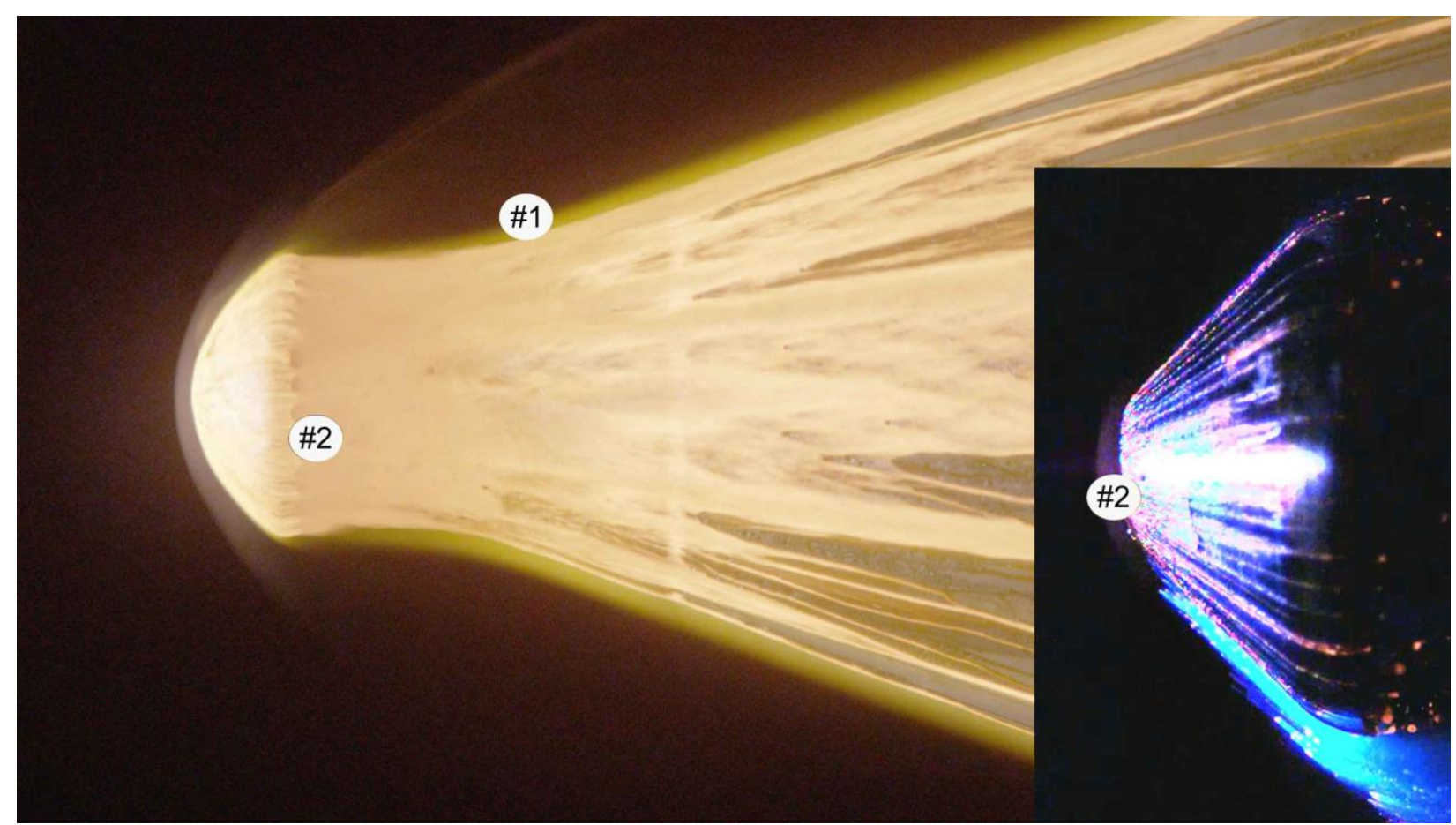

Figure 9. High contrast Red Epic image of Tamdakht\#1, with a white spots marking the line of sight probed by the Echelle instrument during run \#1 (Oct. 2016) and run \#2 (July 2017). Same for iron meteorite (inset).

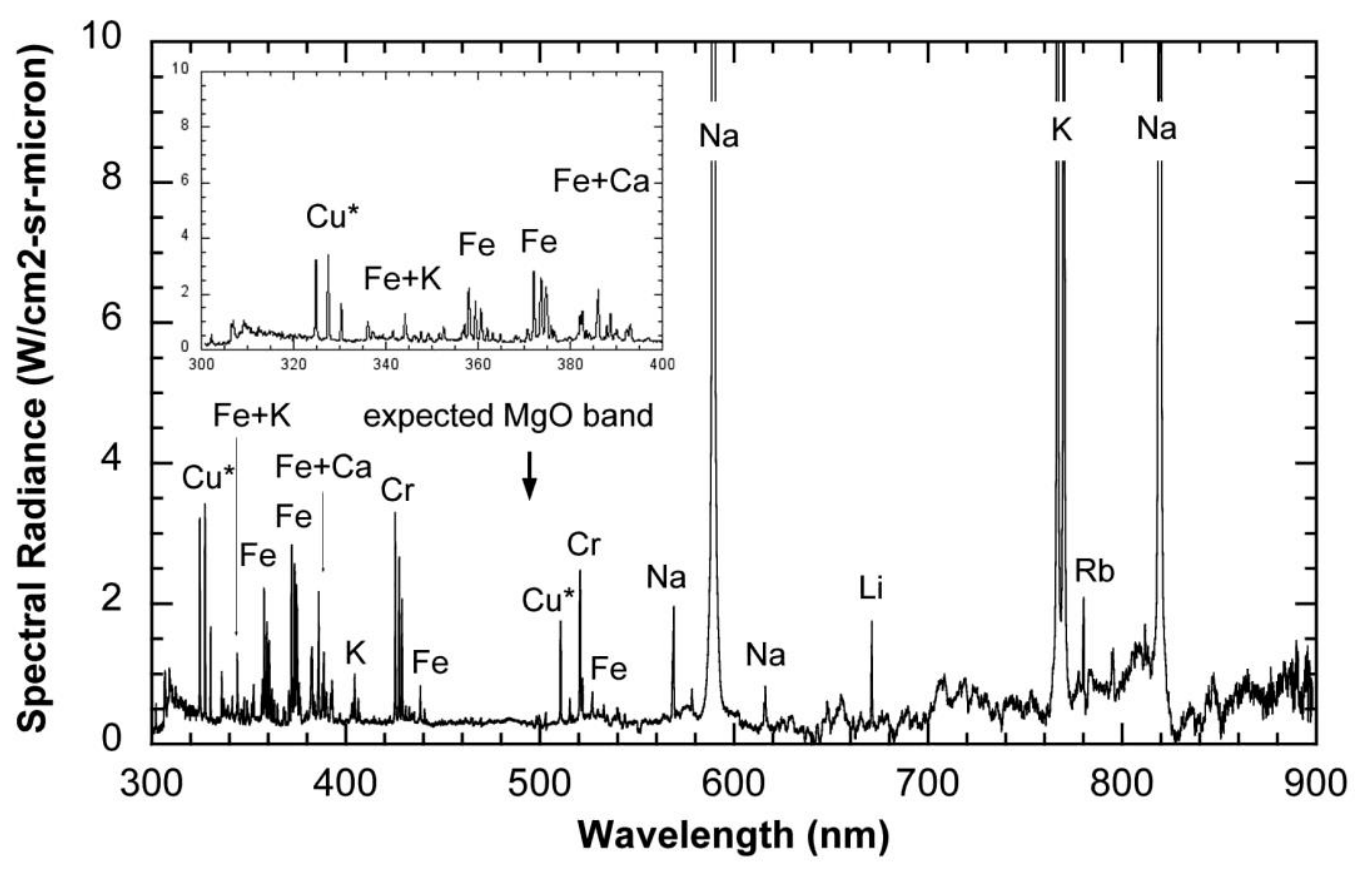

Figure 10. Echelle spectrum of the Tamdakht \#1, after subtraction of a continuum background.

After subtraction of a $2200 \mathrm{~K}$ blackbody continuum (Fig. 10), there is no clear sign of the expected $\mathrm{MgO}$ molecular band emission. Residual wiggles in the spectrum are instrumental in nature due to imperfect alignment of the Echelle orders. This problem is less severe at near-UV wavelengths, where the orders overlap well and cover a narrow wavelength regime. Here, a strong $\mathrm{OH}$ band is detected at $310 \mathrm{~nm}$, the result of water leaking into the flow of the Arcjet at the time of the measurement. Significant near-UV continuum emission may be reflected Arcjet emission. 


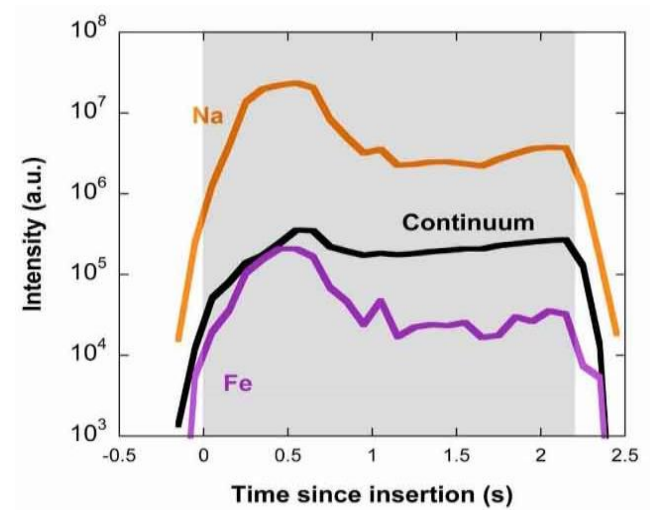

Figure 11. Time evolution of the $\mathrm{Na}$ and $\mathrm{Fe}$ emissions in Tamdakht \#1.

color than that from the Arcjet. The nature of that emission remains unknown.

Figure 11 shows the time evolution of the sodium and iron emissions and that of the continuum emission. Sodium and iron emissions were slightly stronger than average just after insertion in the flow. The intensity ratio stayed nearly the same. The relative level of differential ablation, whereby sodium in more volatile minerals is lost first before iron is lost, remained constant.

\section{Iron meteorite (Campo Del Cielo)}

The iron meteorite sample was to be exposed for 5 seconds, but the sample receded so fast by melting and evaporation that we stopped the test at 3 seconds. Figure 12 shows selected frames captured by the high speed camera. Within 0.1 seconds of exposure, streams of iron melt are observed on the surface. Similar to Basalt and Tamdakht, the melt flow reached the LI-2200 stem, graphite holder, and copper cooling cone.

A diffuse light blue light was observed when small segments were spalled from the sample (Fig. 12). This light was a different
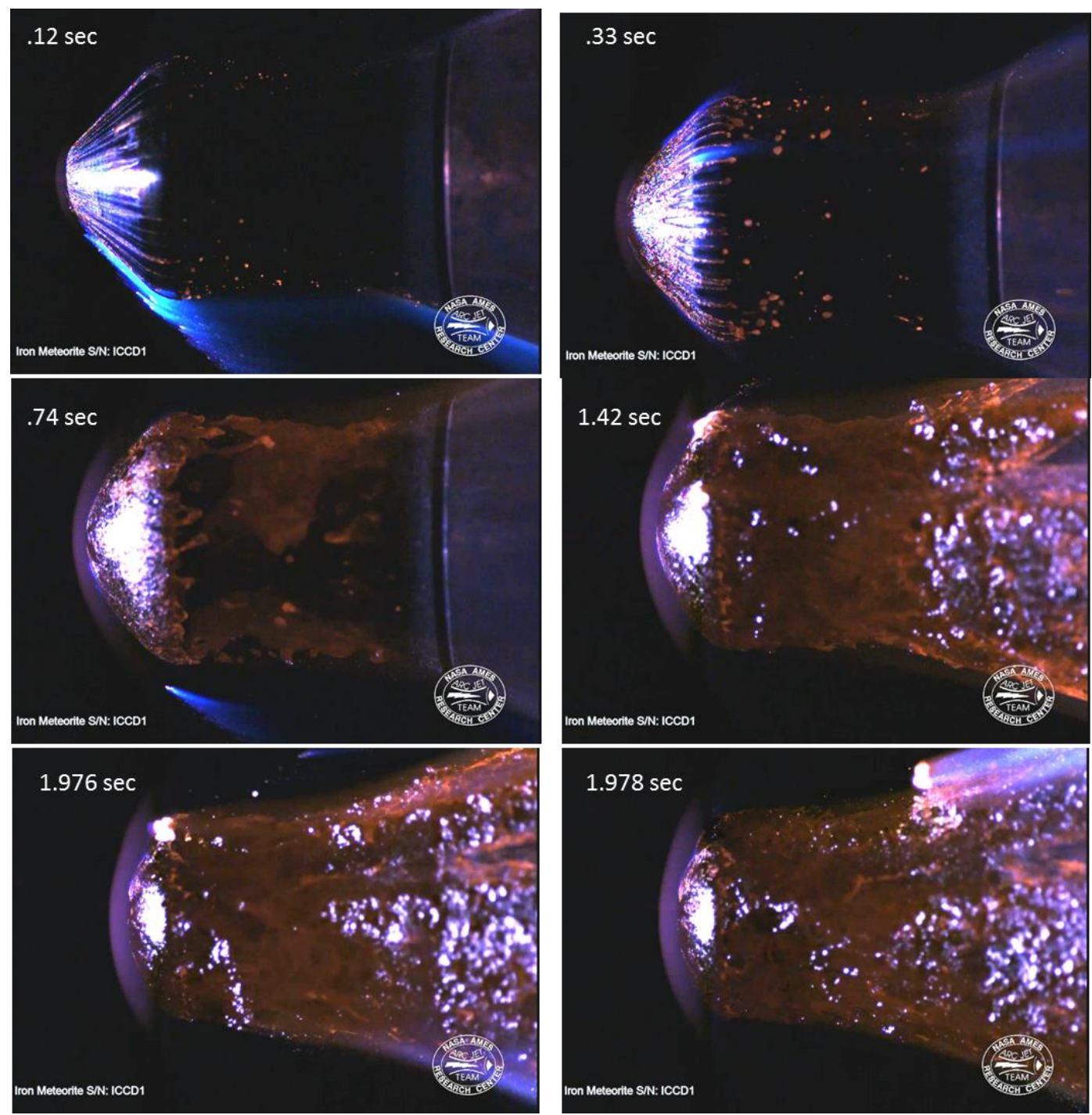

Figure 12. Iron meteorite (Campo De Cielo) in Arcjet exposure. 
Campo De Cielo is known to contain an abundance of refractory silicate inclusions. These inclusions behaved differently from the rest of the sample. They were not melting at the same rate as the rest of the sample, which is comprised mainly of metallic iron. Instead, inclusions simply dissociated form the sample from time (Fig. 12).

Iron Meteorite (ICCD1) Pyrometer Data: Emissivity 0.3
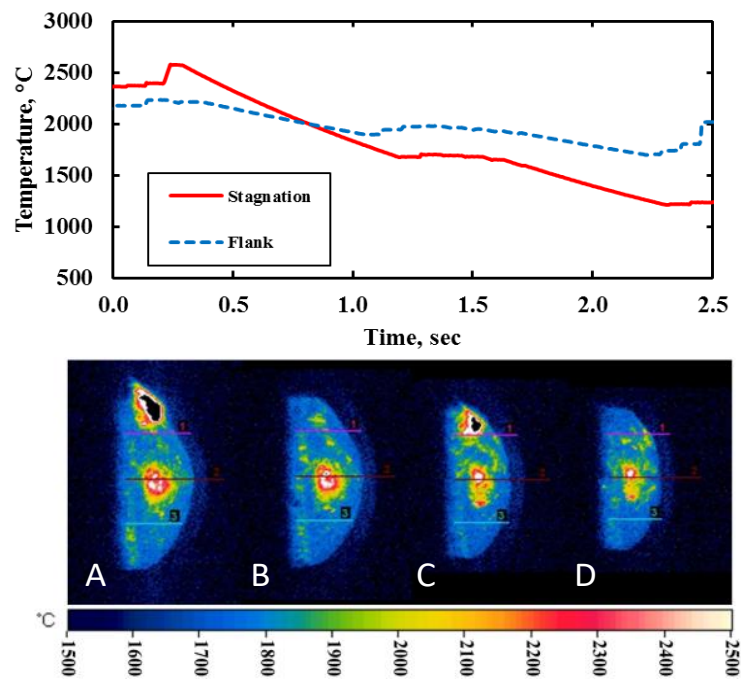

Figure 13. Surface temperature evolution for the iron meteorite. Flow direction is from right to left. (A) $1.0 \mathrm{~s},(\mathrm{~B}) 1.1 \mathrm{~s},(\mathrm{C}) 1.42 \mathrm{~s},(\mathrm{D}) 1.5 \mathrm{~s}$.

Tamdakht\#2 again showed the atomic line emissions of $\mathrm{Na}, \mathrm{K}, \mathrm{Li}$ and $\mathrm{Rb}$, as well as $\mathrm{Fe}$ and $\mathrm{Cr}$.

The flow around the iron meteorite was probed near the stagnation point (Fig. 9, inset), and the measured spectrum showed strong air plasma emissions from oxygen and nitrogen (Fig. 14). Other detected emissions were likely contaminant atoms from the Arcjet electrodes $\left(\mathrm{Cu}^{*}\right)$. Weak emission lines of iron were detected also, as well as weak emissions from sodium. The origin of the sodium is undetermined.

Consistent with the lower surface temperatures measured at mid-IR wavelengths and by the pyrometers, the continuum spectrum of the iron meteorite was also weaker than that of the stony ordinary chondrite meteorite.
The measured surface temperatures of the iron meteorite are shown in Figure 13 (top). Due to high conductivity of iron, the stagnation and flank pyrometer values are very similar, both in the range of $2300^{\circ} \mathrm{C}$ to $2600^{\circ} \mathrm{C}$. These temperatures are well above the melting point of iron at $1538{ }^{0} \mathrm{C} .{ }^{10}$ However, these values are still below the boiling point of $2750^{\circ} \mathrm{C}$. The sample was completely melted at 2.2 seconds.

The temperature map based on mid-IR imaging is shown in Figure 13 (bottom). The presence of the hard silicate refractory inclusions are shown in the captured frames as peaks in temperature on those parts. Here, the inclusions reach higher temperatures than the surrounding material, in part because they recess slower and are thus exposed to hotter regions of the flow. The surface temperature ranges from $1800^{\circ} \mathrm{C}$ to $2400^{\circ} \mathrm{C}$ near the inclusions, well above the melting point of iron.

The Echelle spectrograph obtained well-exposed spectra for both the stony ordinary chondrite (second sample of Tamdakht \#2) and the iron meteorite (Fig. 14).

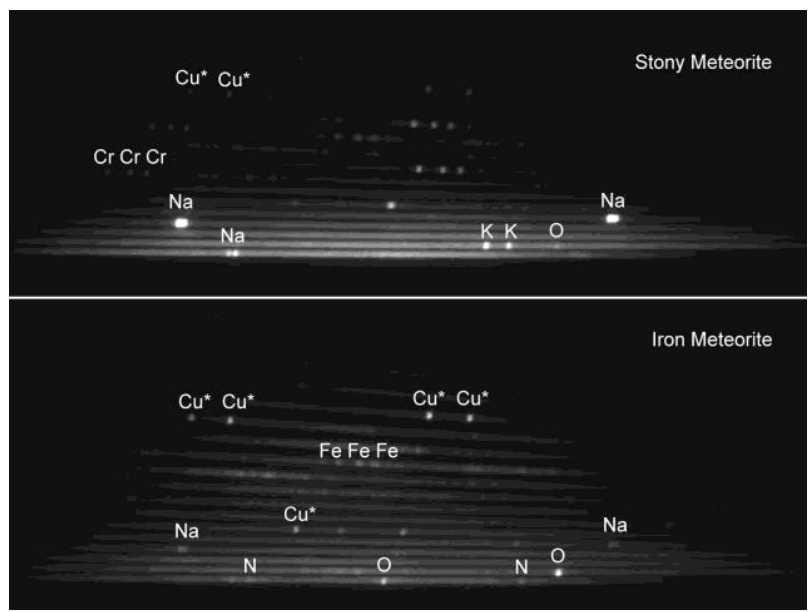

Figure 14. Echelle spectra of the stony (top) and iron (bottom) meteorites.

\section{Fused Silica}

Fused Silica was tested as one of the terrestrial analogs that is being used for the development of high-fidelity ablation models. Three Fused Silica samples were tested during the campaign. In the first phase of testing the samples were exposed for 2 seconds similar to the Tamdakht meteorite. Fused Silica behaved very differently in the test compared to Basalt or the two meteorites. The rate of recession for Fused Silica was significantly lower compared to Basalt and the two Tamdakht samples. A much slower moving melt layer is observed in these tests, which we attribute to a higher viscosity of the silica melt. Less than 2-mm at the stagnation point of recession was observed in phase-1 tests. During phase 2 testing, the two Fused Silica samples were exposed longer, for a total of 5.0 seconds. The recession at the stagnation point after this time was $3.16 \mathrm{~mm}$. 


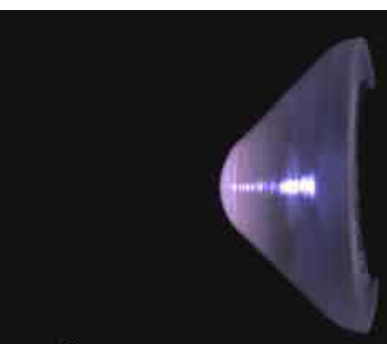

$0 \mathrm{sec}$

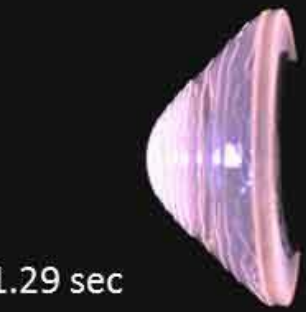

$2.44 \mathrm{sec}$

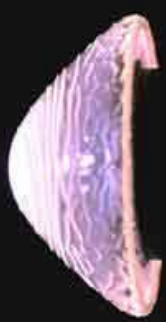

\section{$4.18 \mathrm{sec}$}

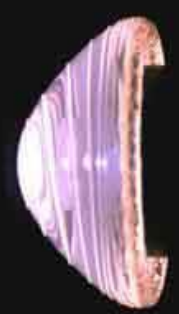

$.58 \mathrm{sec}$

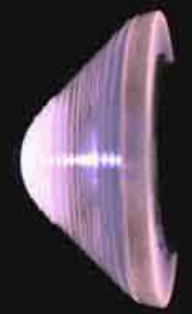

$2.15 \mathrm{sec}$

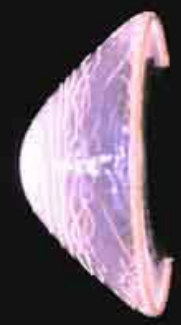

$3.07 \mathrm{sec}$

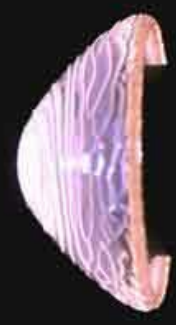

$4.93 \mathrm{sec}$

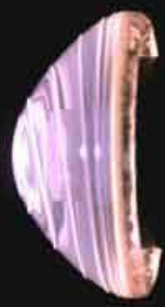

Figure 15. Fused Silica during 2nd phase testing.

Figure 15 shows the various stages of glass melt during the 5 -second exposure. At first, the glass melting starts near the stagnation point. By 0.5 second a thin melt layer forms all over the surface with several rings formed inside the melt layer as shown in Fig. 15. By the end of the exposure, the melt layer has only slightly flowed over the shoulder of the model. This behavior is very different from what we witnessed in Basalt and the two meteorites. While a thin layer of re-deposits of glass vapor was observed on the graphite holder and copper cooling cones, there was no evidence of melt flow outside of the sample on the LI-2200 stem or the holder. The waves caused by glass melting were still present on the surface of the Fused Silica sample after the sample had cooled down. 


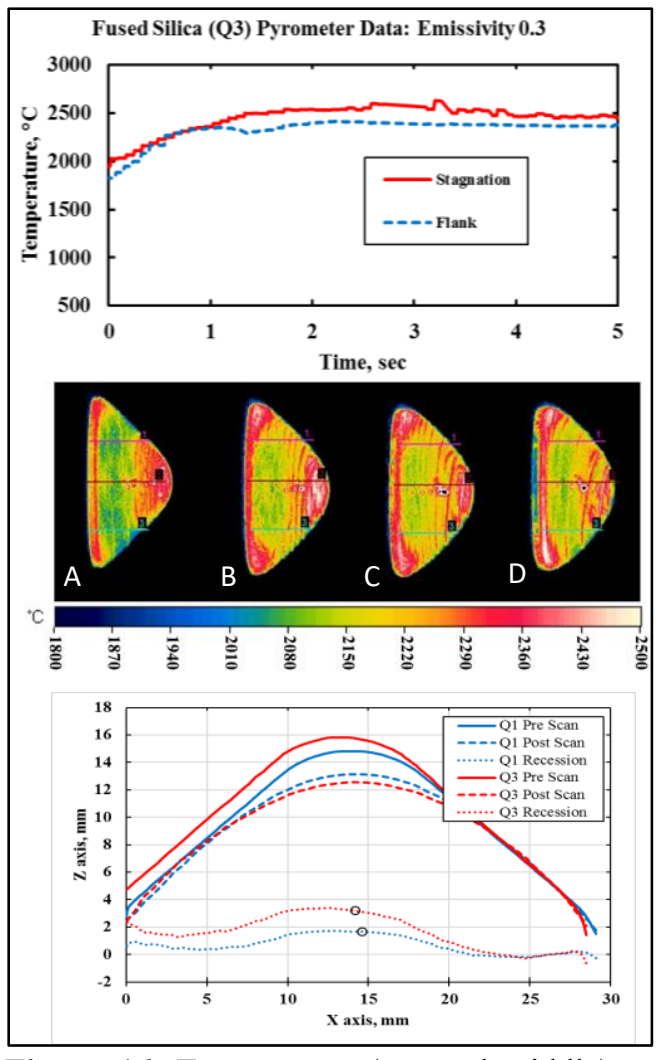

Figure 16. Temperature (top and middle) and recession (bottom) profile for fused Silica. (A) $0.1 \mathrm{~s}$; (B) 1.0s; (C) 2.0s; (D) 5.0s.

The emission spectra were also quite different from those of the meteorites. Figure 17 shows the extracted spectrum captured during the Fused Silica\#1 exposure in the first run, when the $\mathrm{OH}$ band of water was present. The 310-nm OH band is well detected. Atomic emission lines are from copper (a contaminant in the Arcjet flow), with weak lines from air plasma emissions $(\mathrm{O}, \mathrm{N})$, and other weak lines from sodium and potassium. The sodium and potassium appear to be an impurity in the glass, because these emissions are not detected in the free flow (Fig. 18, bottom). A $4000 \mathrm{~K}$ black body emisison was fitted to the observed continuum (thin dashed line), leaving mainly the $\mathrm{OH}$ band unaccounted for (Fig. 17). This temperature is much higher than the surface temperature.

\section{Discussion}

\section{A. Pre-test predictions.}

A detailed computational fluid dynamics study (CFD) analysis was performed using a NASA flow solver, DPLR $^{12}$, in order to characterize the flow conditions during exposure. Figure 18 shows three different configurations: a) pre-test, b) post-test and c) during the test (when melt flow is significant). The CFD predictions of the flow temperature distribution around the test article for these three configurations are shown in the top panels of Fig. 18. Near the stagnation point and around the copper cones, the temperatures are extremely high, in the range of $5000^{\circ} \mathrm{C}$. However, due to a backward facing step near the LI-2200 stem, there is a localized cooling region where the flow separates, re-circulates, and the temperature drops to below $1500^{\circ} \mathrm{C}$. This pre-test analysis gave us the confidence of selecting LI-2200 stem for insulation.
Figure 16 (top) shows the surface temperature for the final Fused Silica sample. The melting point of fused silica is listed as temperatures reached $2500^{\circ} \mathrm{C}$ (assuming an emissivity value of 0.3 ), which again well exceeds the boiling point.

in Figure 16 (mid panel). The video frames show the same swirl pattern as a difference in temperature around the swirl. The temperature values range between $2100^{\circ} \mathrm{C}$ to $2500^{\circ} \mathrm{C}$ and are Aistent with the pyrometer data. slower melt flow and ablation due to very high viscosity. Therefore, for sample Fused Silica\#1 subjected to 2.0 second exposure, the magnitude of recession was only $1.29 \mathrm{~mm}$, corresponding to a rate of $0.65 \mathrm{~mm} / \mathrm{s}$ (Fig. 16, bottom panel). Silica sample \#3, was tested for a longer 5 seconds, corresponding to a rate of $0.63 \mathrm{~mm} / \mathrm{s}$, in good agreement (Fig. 16).

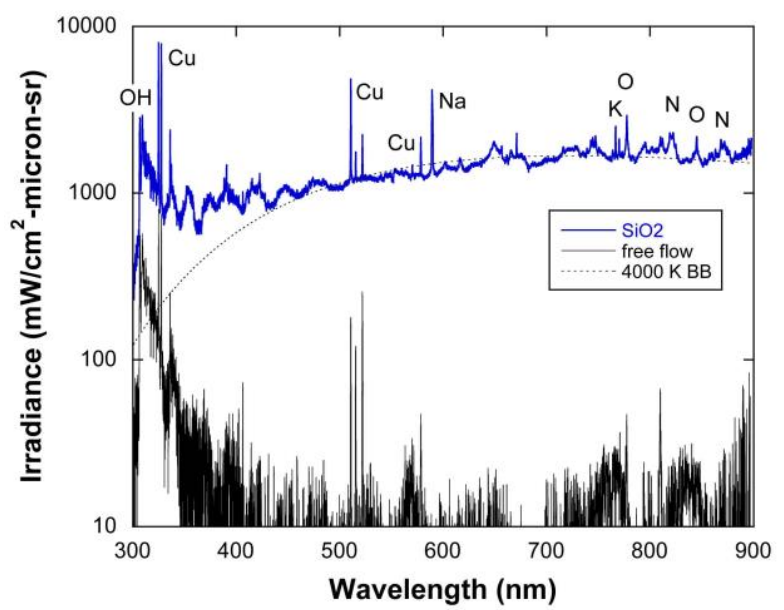

Figure 17. Fused silica $\left(\mathrm{SiO}_{2}\right)$ spectrum during exposure. 
A
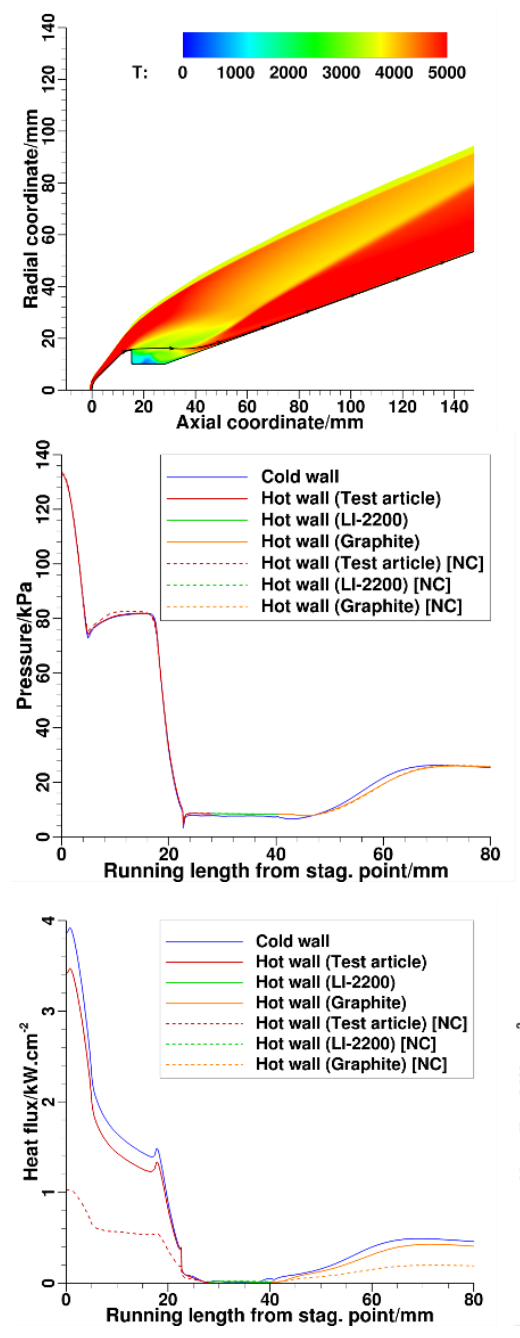

B
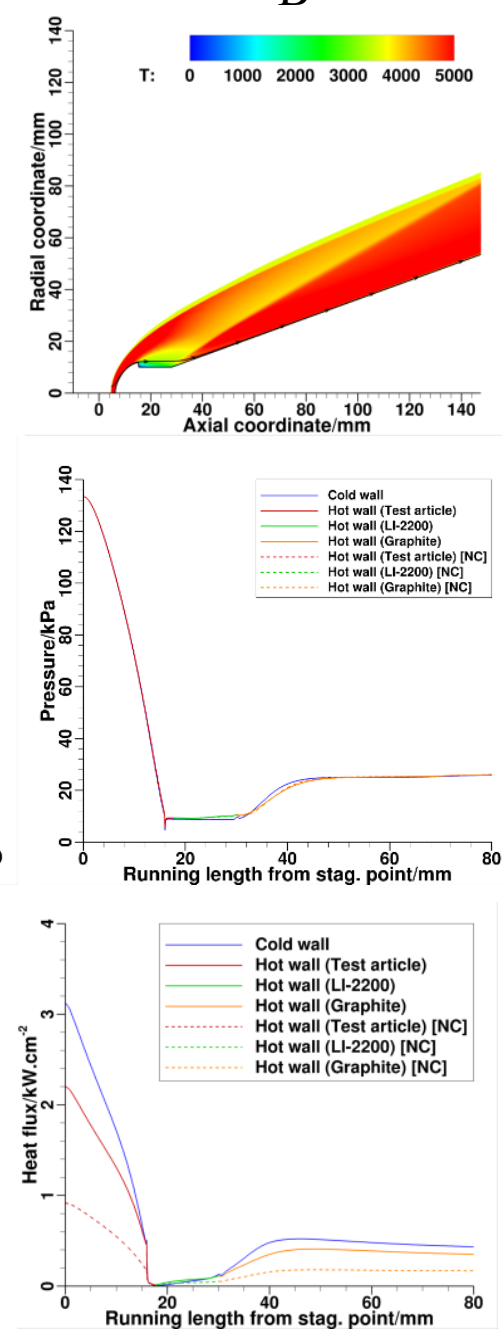

C
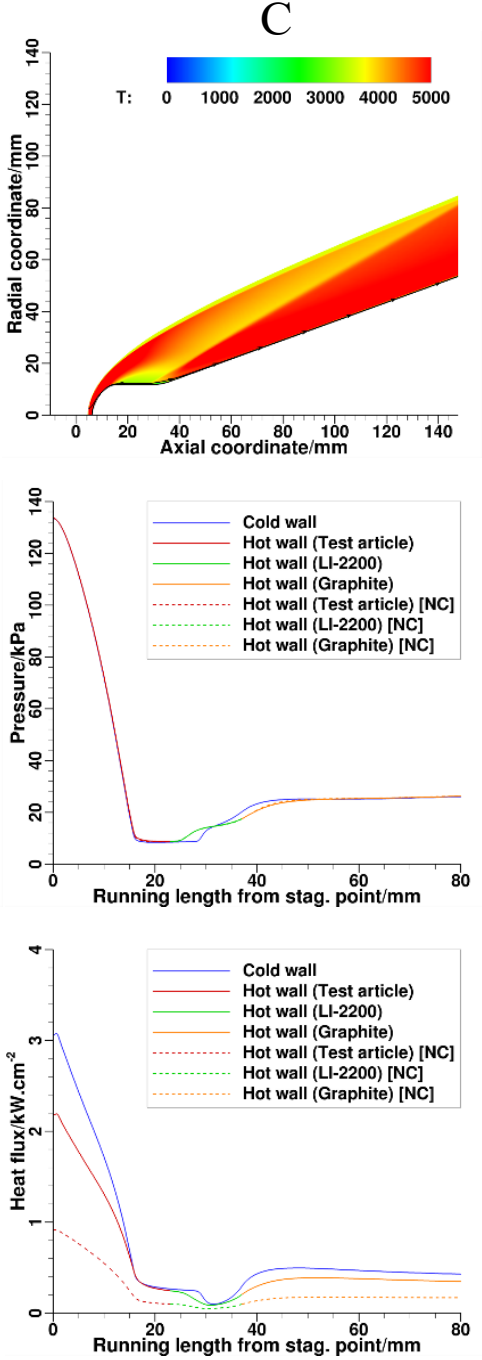

Figure 18. Pre-test and post-test Pitch Temperature (top), Pressure (middle) and Heat Flux (bottom). (A) Pre-test; (B) Post-test; (C) During test with no negative step. 

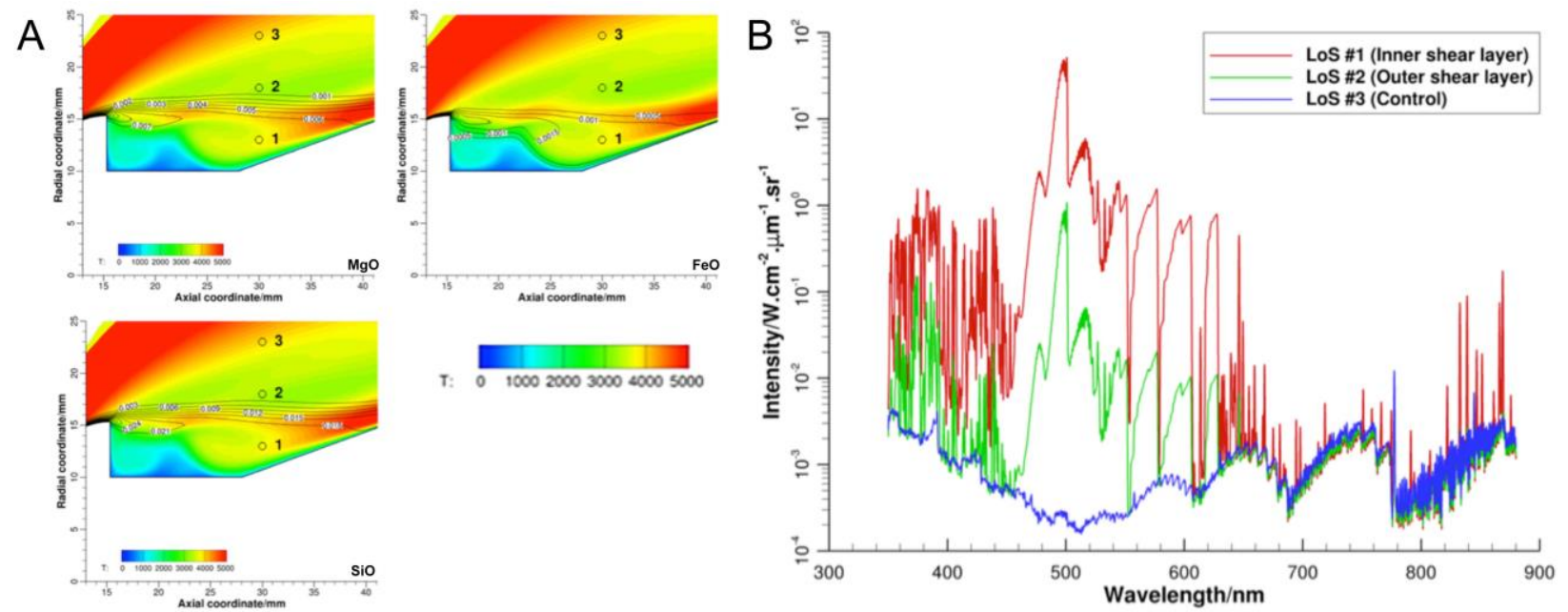

Figure 19. Predicted emission spectrum of ablated meteoric vapor. (A) The concentration of diatomic species (oxides) in the flow and recommended line of sight. Contours are in atoms per $\mathrm{cm}^{3}$, while colors indicate the flow temperature in K. (B) Synthetic spectra predicted for the three lines of sight shown by open circles.

The pressure distribution for these configurations are shown in Fig. 18 (middle panels). According to these predictions, the stagnation pressure is about $135 \mathrm{kPa}$ and stays constant through-out the test duration. However, the pressure distribution changes significantly away from the stagnation point due to change in shape as shown in Fig. 18 (middle panels).

The predicted heat flux distributions are shown in Fig. 18 (bottom panels). The maximum cold-wall heat flux for pre-test configuration is about $4000 \mathrm{~W} / \mathrm{cm}^{2}$ near the stagnation point. However, as the article starts to recede the heat flux also changes and the cold-wall heat flux goes down to $3100 \mathrm{~W} / \mathrm{cm}^{2}$ for post-test configuration. When melt-flow is prominent the heat-flux value does not drop as drastically near the baseline. The corresponding hot-wall heat flux values for pre-test configuration assuming catalacity is $2700 \mathrm{~W} / \mathrm{cm}^{2}$ and after recession it reduces to $2200 \mathrm{~W} / \mathrm{cm}^{2}$. Note the values are considerably reduced to $\sim 1000 \mathrm{~W} / \mathrm{cm}^{2}$ when non-catalytic flow is assumed as shown in Fig. 18 (lower panels).

Based on this flow field, a theoretical spectrum was calculated for three positions just behind the test article, in the inner shear layer, the outer shear layer and at a control position higher in the flow (Fig. 19). The predicted emissions under these conditions are dominated by $\mathrm{MgO}$ band emission. The air plasma contributes strong First Positive band emission from $\mathrm{N}_{2}$ as well as weak oxygen and nitrogen atom line emissions. Sodium and Potassium emissions are not calculated. The model did not include melting.

\section{B. Post-test results.}

This experiment aimed to gather data needed for the development of high-fidelity models for meteoroid ablation. Preliminary coupled CFD-material response calculations of the experiments suggests an effective heat of ablation for Tamdakht of $\sim 2 \mathrm{MJ} / \mathrm{Kg}$. This suggests that the effective heat of ablation is well below the canonical value of $8 \mathrm{MJ} / \mathrm{kg}$ for ordinary chondrite vaporization ${ }^{13}$, and lower than in the case of stagnant melts for laser ablation of Tamdakht meteorites ${ }^{14}$. This re-enforces the observation that the surface recession is dominated by melt flow. Melt flow is a more energetically efficient mode of mass removal.

The ablation parameter affects the height of the airburst of small impacting asteroids, and therefore the footprint of the damaging shockwave on the ground. Bias in the ablation parameter toward the low-end would result in a lower altitude airburst, and therefore a larger ground damage footprint.

Although the conditions improved compared to prior exiperments ${ }^{15}$, it should be noted that the conditions achieved in the Arcjet are still less intense than those expected in flight. At more flight-like conditions more vaporization would be expected.

Distinct differences were observed between predicted and observed emission spectra. In part, this is due to the lack of melting in the models. Emission was mainly observed from the alkali metals that emit from the ground state. This implies that such metals are ideal for artificial meteors ${ }^{16}$. The evaporated vapor has lower excitation temperatures than expected if the material was excited in the shock wave. Instead, the ablated material was excited in the wake of the meteoroid. 


\section{Conclusions}

A successful test campaign of meteorites and terrestrial analogs was conducted in the Interactive Heating Facility (IHF) at NASA Ames Research Center. Data acquired during this test included high speed video films, optical spectroscopy, surface temperature measurements with help of optical pyrometers and mid-infrared cameras, laser surface scans and 3 dimensional X-ray CT scans.

Exposure to the Arcjet plasma flow caused significant melt in the stony Tamdakht and the iron Campo Del Ceilo meteorites as well as in basalt samples. The rate of ablation was significantly faster in both Basalt and the meteorite samples compared to Fused Silica samples, presumably due to a lower viscosity of Basalt and Tamdakht melts compared to those of Fused Silica. From the measured rate of recession, an effective heat of ablation was calculated that is much lower than the traditional assumed value.

High speed video shows that material is also lost by spallation (Basalt more than stony meteorites) and the shedding of refractory inclusions (iron meteorite). The loss of inclusions offers new insight into how high melting point materials can survive reentry when carried by lower melting point matrix.

The analysis from Tamdakht emission spectra shows lower excitation temperatures than expected, with emissions being primarily from alkali-metals that emit from the ground state. This data will improve our insight into how to interpret natural meteor spectra during atmospheric entry.

\section{Acknowledgments}

Dinesh Prabhu of NASA Ames Research Center performed the CFD simulations. Imelda Teresa Salinas and Erika Rodrigues of the IHF led the team that successfully conducted these tests. Supplemental spectroscopy and imaging was provided by Zev Hoover (Dexter Southfield schools), Megan McDonalds (NASA Ames), Rich Tansey, Jim Albers, and Mike Koop (Lockheed Martin and the SETI Institute), and Fabio Teixeira (Hypercubes). Ron Dantowitz of Dexter Southfield schools facilitated the effort. Important contributions were also made by Francesco Panerai, Jose Chavez, Greg Gonzales, STAR laboratory, Sputnik machine shop, Daniel Ostrowski, Andrew Torricelli and Jeremy Aires. This work is supported by the Asteroid Threat Assessment Project (ATAP) management team and the NASA Planetary Defense Program Coordination Office (PDCO).

\section{References}

[1] Arnold, J. O., Burkhard, C. D., "Maturation of the Asteroid Threat Assessment Project", IPPW-14, June 11-16 Abstract (2017).

[2] National Research Council, "Defending Planet Earth: Near-Earth Object Surveys and Hazard Mitigation Strategies", Natl. Acad. Press, Washington D.C. (2010).

[3] Popova, O. P., et al., "Chelyabinsk airburst, damage assessment, meteorite recovery, and characterization", Science, 342(6162), 1069-1073 (2013).

[4] Lyne, J. E., Tauber, M., "Origin of the Tunguska event”, Nature, 375, 638-639 (1995).

[5] Weisberg M. K., Smith, C., Benedix, G., Folco, L., Righter, K., Zipfel, J., Yamaguchi, A., ChennaouiAoudjehane, H., "The Meteoritical Bulletin, No. 95", Meteoritics \& Planetary Science 44, Nr 3, 1-33 (2009).

[6] Cassidy W. A., Renard, L. M., "Discovering Research Values in the Campo del Cielo, Argentina, meteorite craters", Meteoritics and Planetary Science, 31, 433-448 (1996).

[7] Buchwald, V. F., "The Handbook of Iron Meteorites, Their History, Distribution, Composition and Structure", The University of California Press, Berkeley (1975).

[8] Jenniskens, P., "Observations of the Stardust Sample Return Capsule Entry with a Slitless Echelle Spectrograph", Journal of Spacecraft and Rockets, 47, No. 5, 718-735 (2010).

[9] Larsen, E.S., "The Temperature of Magmas", American Mineralogist, Volume 14, pages 81-94 (1929).

[10] Online database, website: http://www.chemicalelements.com/elements/fe.html (Last viewed: 5/2018).

[11] Silica glass (60676-86-0) Material Safety Data-sheets, website: http://www.chemicalbook.com/ProductMSDSDetailCB1199394_EN.html (Last viewed: 5/2018).

[12] Wright, M. W., White, T., Mangini, N., "Data Parallel Line Relaxation (DPLR) Code User Manual Version 4.01.1,” NASA/TM-2009-215388 (2009).

[13] Öpik, E. J., "Physics of Meteor Flight in the Atmosphere", Dover Press (1958).

[14] White, S. M., Stern, E. C., "Laser ablation experiments on the Tamdakht H5 chondrite". 80th Annual Meeting of the Meteoritical Society 2017 (LPI Contrib. No. 1987), id. 6130 (2017). 
[15] Loehle, S., Zander, F., Hermann, T., Eberhart, M., Meindl, A., Oefele, R., Vaubaillon, J., Colas, F., Vernazza, P., Drouard, Al, Gattacceca, J., "Experimenal Simulation of Meteorite Ablation during Earth Entry using a Plasma Wind Tunnel", Astrophysical Journal 837, Issue 2, article id. 112, 10 pp (2017).

[16] Abe, S., Okajima, L., Sahara, H., Watanabe, T., Nojiri, Y., Nishizono, T., "Artificial meteor test towards: Ondemand meteor shower", Proceedings of the International Meteor Conference, Egmond, the Netherlands, 2-5 June 2016, Eds.: Roggemans, A., Roggemans, P., ISBN 978-2-87355-030-1, pp. 17 (2016). 